\title{
Revisiting Swiss temperature trends 1959-2008
}

\author{
Paulo Ceppi, Simon C. Scherrer*, Andreas M. Fischer, Christof Appenzeller \\ *Corresponding author (simon.scherrer@meteoswiss.ch; +41-44-256-92-53) \\ Climate Services, Federal Office of Meteorology and Climatology (MeteoSwiss), \\ Krähbühlstrasse 58, 8044 Zürich, Switzerland
}

\section{Keywords}

altitude dependence of temperature trends; atmospheric circulation patterns; gridded temperature; climate change; snow-albedo feedback; Switzerland; Alps; ENSEMBLES

\begin{abstract}
Temperature is a key variable for monitoring global climate change. Here we perform a trend analysis of Swiss temperatures from 1959-2008, using a new $2 \times 2 \mathrm{~km}$ gridded data set based on carefully homogenised ground observations from MeteoSwiss. The aim of this study is twofold: first, to discuss the spatial and altitudinal temperature trend characteristics in detail and second, to quantify the contribution of changes in atmospheric circulation and local effects to these trends.

The seasonal trends are all positive and mostly significant with an annual average warming rate of $0.35^{\circ} \mathrm{C} /$ decade $(\sim 1.6$ times the northern hemispheric warming rate), ranging from 0.17 in autumn to $0.48^{\circ} \mathrm{C} /$ decade in summer. Altitude-dependent trends are found in autumn and early winter where the trends are stronger at low altitudes $(<800 \mathrm{~m}$ asl $)$, and in spring where slightly stronger trends are found at altitudes close to the snow line.

Part of the trends can be explained by changes in atmospheric circulation, but with substantial differences from season to season. In winter, circulation effects account for more than half of the trends, while this contribution is much smaller in other seasons. After removing the effect of circulation, the trends still show seasonal variations with higher values in spring and summer. The circulation-corrected trends are closer to the values simulated by a set of ENSEMBLES regional climate models, with the models still tending towards a trend underestimation in spring and summer.

Our results suggest that both circulation changes and local effects are important to explain part of recent warming in spring, summer and autumn. Snow-albedo feedback effects could be responsible for the stronger spring trends at altitudes close to the snow line, but the overall effect is small. In autumn, the observed decrease in fog frequency might be a key process in explaining the stronger temperature trends at low altitudes.
\end{abstract}

\section{Introduction}

During the 20th century, the effects of global warming have been observed worldwide in the form of positive temperature trends. On the global scale, mean surface temperatures have increased by $0.74^{\circ} \mathrm{C}$ during the last century, while climate models predict even faster warming rates for the next decades. This increase in mean temperatures is expected to have substantial ecological, economic and societal impacts, and these effects will not be homogeneous across the globe. It is believed that coastal, mountain and high-latitude regions will be amongst the most affected areas (IPCC, 2007a).

The attribution of local warming trends to global climate change is made difficult by the large number of physical processes influencing temperature variability (IPCC, 2007b). Recent European warming may have been driven by changes in a number of physical parameters, such as incoming shortwave radiation and aerosols (Wild et al., 2005; Wild, 2009; Philipona et al., 2009; van Oldenborgh et al., 2009), soil moisture (Fischer et al., 2007), fog occurrence frequency (Vautard et al., 2009) and atmospheric circulation patterns (Corti et al., 1999; van Oldenborgh et al., 2009; Vautard and Yiou, 2009). The representation of some of these processes in current state-of-the-art global and regional climate models is still inaccurate, which leads to potential discrepancies between model-based and 
observed trends (van Oldenborgh et al., 2009) and will likely affect the accuracy of regional warming projections.

A key aspect for climate change projections in the Alpine region is the altitude dependence of surface temperature trends. While most reanalyses and model predictions indicate an increase of warming effects with altitude in the mid-latitude lower to middle troposphere (see Fig. 10.7 in IPCC, 2007b, p. 765), studies based on ground observations yield less clear results, sometimes in contradiction with model-based analyses (e.g. Bradley et al., 2004; Pepin and Seidel, 2005; Appenzeller et al., 2008). The altitude dependence of surface temperature trends is likely to be influenced by several of the physical processes described above, particularly by changes in atmospheric circulation and snow-albedo feedback effects. It has been speculated that the observed decreases in snow pack in many mid-latitude mountain regions (e.g., the Alps, Himalayas) might induce a stronger atmospheric warming at elevations where the occurrence of a closed snow cover has diminished (Im et al., 2010; Pepin and Lundquist, 2008).

In this paper, we estimate annual and seasonal Swiss temperature trends over 1959-2008 using highresolution $(2 \times 2 \mathrm{~km})$ gridded data from the MeteoSwiss ground measurement network. The purpose of this study is twofold: first, to discuss the spatial and altitudinal temperature trend characteristics, and second, to quantify the impact of changes in atmospheric circulation and other local effects on the magnitude of the trends.

Because the impact of an increase in mean temperatures is expected to be particularly strong in mountainous regions (see e.g. OcCC, 2007; IPCC, 2007a), knowledge of the magnitude and elevation dependence of warming effects is vital for an Alpine country like Switzerland. Furthermore, a detailed understanding of the mechanisms controlling temperature trends is essential for the accuracy of future warming projections.

\section{Data and methods}

\subsection{Observational temperature data}

A new gridded data set of monthly temperature anomalies is used in this paper. The gridded temperatures were computed using carefully homogenised data from 91 stations evenly distributed across Switzerland (Begert et al., 2005) and situated at heights ranging from 203 to $3580 \mathrm{~m}$ asl (Fig. 1). At each station, the anomalies were calculated with respect to the 1961-1990 reference period. Note that 37 of the 91 temperature series used for gridding are not complete, i.e. the number of stations effectively used in the computation of gridded temperatures fluctuates and is always smaller than 91.

The right panel of Fig. 1 shows the height distribution of the stations and of the gridpoints. In general, the stations reproduce the altitude distribution of the Swiss territory reasonably well, even though lowaltitude regions are slightly overrepresented. Station coverage is scarcer at high altitudes, and there are only two stations above $2700 \mathrm{~m}$ asl. This means that the temperatures calculated for high-altitude gridpoints are based on a small number of stations and are thus subject to relatively large uncertainties.

Monthly temperature anomalies were spatially interpolated onto a regular longitude-latitude grid with a grid spacing of 1.25 degree minutes (approx. $2 \mathrm{~km}$ ). The interpolation encompasses two steps: first, a second-order polynomial in elevation is estimated by non-linear least squares to describe a large-scale (i.e. Switzerland-wide) vertical dependence of temperature anomalies. In the second step, the residuals of this vertical model are interpolated horizontally using a weighting scheme with topographically modified (i.e. non-Euclidean) distances, somewhat similar to those proposed by Deng and Stull (2005). The distance scheme ensures that topographic barriers are respected in the horizontal interpolation, if temperature residuals reveal regional stratification (i.e. vertical dependence not explained in the first step). For example, a measurement (residual) at a valley station is weighted more strongly in the alongvalley direction than at the slopes of the adjacent ridges. The degree of stratification is estimated individually for each month by performing interpolation with several distance schemes and selecting the scheme with the smallest cross-validation error. A paper describing the interpolation method in detail is in preparation (C. Frei, pers. comm.).

\subsection{Regional climate model data}

A trend analysis is performed on regional climate model temperature data to compare model-based trends with observations in the period 1959-2008. Raw model output from regional climate models (RCMs) of the European FP6-ENSEMBLES project (van der Linden and Mitchell, 2009) is used. These RCMs are driven by six coupled atmosphere-ocean global circulation models (GCMs), one of 
which is run in three sensitivity configurations that can be considered independent from each other. The GCMs are not forced with ERA-40 boundary conditions and represent only random interannual and decadal variability. We therefore assume that in a first-order approximation circulation-induced trends cancel in a multi-model mean perspective (cf. Section 5). In the historic period (until 2000), the models were driven by observed greenhouse gas and aerosol concentrations, while the IPCC A1B scenario was used afterwards (IPCC, 2007a). In total, 21 RCM-GCM chains are used in this study.

\subsection{Trend analysis, principal component analysis and smoothing methods}

We use simple linear regression to estimate the magnitude of temperature trends. Trend significance is assessed with the Mann-Kendall trend test (Mann, 1945; Kendall, 1975), which tests the existence of a monotonic (not necessarily linear) trend. We consider trends to be statistically significant if the $p$-value of the null hypothesis is smaller than 0.05 .

A principal component analysis (PCA, see e.g. Wilks, 2005) is performed to describe the effects of changes in atmospheric circulation. NCEP/NCAR reanalysis data (Kalnay et al., 1996) of mean seasonal $500 \mathrm{hPa}$ geopotential height fields over the North Atlantic and Europe $\left(60^{\circ} \mathrm{W}-40^{\circ} \mathrm{E}, 30^{\circ} \mathrm{N}\right.$ $70^{\circ} \mathrm{N}$ ) are used to determine the most important patterns of atmospheric variability over this region. We assume the obtained principal component (PC) loadings to well represent typical synoptic-scale atmospheric circulation patterns.

LOESS curves (locally weighted scatterplot smoothing; cf. Cleveland et al., 1992) are calculated to fit vertical trend profiles to the data clouds of observations and RCM results.

\subsection{Modelling the temperature evolution by regression analysis}

\subsubsection{Statistical model formulation}

We quantify the contribution of atmospheric circulation effects on the Swiss temperature evolution by regression analysis. By doing so, we assume that we can represent temporal changes in atmospheric circulation with principal components (PCs) of geopotential height data. All other effects (including the large-scale effect of greenhouse gas forcing as well as possible local feedbacks and interactions) are part of the error term in the regression model. The regression model can be described as follows:

$$
T_{O B S}(t)=\sum_{i=1}^{10} \beta_{i} P C_{i}(t)+\varepsilon(t)
$$

$T_{O B S}(t)$ denotes the spatially-averaged Swiss temperature anomalies, while the PCs represent the dominant modes of atmospheric variability. Note that there was no detrending prior to the PCA in order to include possible trends in geopotential height induced by climate change as well as natural decadal variations. By design, the potential contributions of other effects not associated with circulation are hidden in the error term $\varepsilon(t)$ and we cannot distinguish between possible signals and model errors. After determining the coefficients of the above equation, we can compute "circulationderived" temperature anomalies and trends by combining the estimated regression coefficients with the time series of the PC coefficients. Using the difference between observed and circulation-derived temperatures ("residual component"), we calculate the warming component that is independent of atmospheric circulation, which we call residual trend.

To detect possible altitude effects in the temperature signal of atmospheric circulation, we also performed the same regression analysis at every gridpoint using the PCs selected by the stepwise regression of the spatially-averaged temperatures. This procedure to quantify the spatial distribution of the contribution of circulation is similar to that applied by Abatzoglou and Redmond (2007).

\subsubsection{Model configuration, calibration and validation}

In order to ensure that only those patterns of atmospheric circulation which have an influence on Swiss temperatures are represented in the model, we select the relevant PCs by stepwise regression. The stepwise algorithm is based on the AIC criterion (Sakamoto et al., 1986) and may include any combination of the 10 leading PCs. Depending on the season, five (MAM) to eight (DJF) PCs are kept in the model.

We also performed the regression analysis with a fixed number of PCs (4 and 5; results not shown), but found the stepwise regression model with 10 PCs to best reproduce the observations in both the calibration and validation periods. Limiting the maximum number of PCs to 10 seems a good compromise between two requirements. On the one hand, enough PCs should be included so that all 
circulation patterns that have an influence on temperatures are considered; on the other hand, however, high-order PCs often describe complex patterns which are difficult to interpret and are not representative of common, physically reasonable circulation patterns. In addition, limiting the maximum number of PCs is necessary to prevent the model from being excessively overfit.

To assess the ability of the model to explain interannual temperature variations with atmospheric circulation variables, we calibrated the regression coefficients in the first half of the time series (19591983), which has a weak annual trend of $0.09^{\circ} \mathrm{C} /$ decade ( $p$-value: 0.52 ). We then validated our results by comparing the circulation-derived values with the observations. The correlation between observed and circulation-derived temperatures indicates how much of the interannual variability can be reproduced.

\section{Magnitude and altitude dependence of Swiss temperature trends}

\subsection{Trend magnitude}

Figure 2 shows that the annual and seasonally-averaged temperature trends are positive in all seasons and for all gridpoints. The annual trends range between 0.23 and $0.44{ }^{\circ} \mathrm{C} / \mathrm{decade}$, with a mean value of $0.35^{\circ} \mathrm{C} /$ decade and $90 \%$ of the values within $0.30-0.39^{\circ} \mathrm{C} / \mathrm{decade}$. Thus, on an annual scale, temperatures have been rising quite similarly over all of Switzerland in recent decades and spatial variability is relatively small. In particular, no notable differences are found between the northern and southern side of the Alps, despite the different weather regimes induced by the mountain range. All annual trends are very highly significant, the $p$-values of the trend significance test being smaller than $5 \cdot 10^{-4}$ at every gridpoint.

There are, however, considerable seasonal variations in trend magnitude, with trends being clearly weakest in autumn $\left(0.02\right.$ to $0.38^{\circ} \mathrm{C} /$ decade, mean value: $0.17^{\circ} \mathrm{C} /$ decade $)$ and strongest in summer $(0.34$ to $0.62^{\circ} \mathrm{C} /$ decade, mean: $0.46^{\circ} \mathrm{C} /$ decade). Removing the exceptionally warm summer of 2003 , the summertime trend reduces to $0.39^{\circ} \mathrm{C} /$ decade on average. Trends are generally significant, except in autumn where only lowland regions (below about $800 \mathrm{~m}$ asl) report statistically significant trends. Note that because of the large interannual temperature variability, statistical significance is more difficult to reach in winter than in other seasons.

Contrary to the annual trends, in seasonal resolution some spatial trend patterns can be observed. In particular, the autumn trends show altitudinal dependence, with highest values at low altitudes. The other seasons also feature some patterns in the spatial distribution of trends, but it is difficult to relate such patterns to altitude effects, at least with this kind of representation. More details on the altitude dependence of Swiss temperature trends are given in the next sections.

In general, our results are in good agreement with findings from previous studies on Swiss temperature trends (Begert et al., 2005). Rebetez and Reinhard (2007), who analysed the trends at 12 Swiss stations over the 30-year period 1975-2004, also observed stronger trends in spring and summer than in autumn and winter. A slight tendency toward faster warming at low altitudes was found by Rebetez and Reinhard (2007) and Appenzeller et al. (2008) for autumn.

\subsection{Altitude dependence}

Since we observe spatial variability, altitude effects and temporally changing patterns from one season to another, we assume that the magnitude of the trends must be influenced by phenomena acting on local scales. In this section, we investigate the impact of local physical processes on the altitude dependence of temperature trends by considering the vertical structure of the trends in more detail. Trend profiles, which describe the trend magnitude as a function of altitude, provide a convenient way to visualise the altitude dependence of the trends (Fig. 3). The calculated LOESS fits (cf. Section 2.3) represent an "averaged" relationship between trend magnitude and altitude.

The vertical trend profiles reproduce the altitude effects observed in Fig. 2. In particular, the positive anomaly in autumn at low altitudes is obvious. The gridpoint trends form coherent, structured vertical patterns, which justifies the representation of the data with LOESS fits. Note that because of the small number of high-altitude gridpoints, the fits were calculated up to $3000 \mathrm{~m}$ only. Above this altitude limit, some distinct "branches" can be seen in the gridpoint data in several seasons (e.g. spring), which reflects the fact that the portions of the Swiss territory situated above $3000 \mathrm{~m}$ form obvious clusters of gridpoints with similar trends. 
To visualise the monthly changes in the vertical structure of the trends, we subtract the corresponding mean monthly trend (not shown) from the fitted trend values at each point of the corresponding LOESS profile. We thus obtain deviations of the vertical profiles from the respective mean monthly temperature trends (hereafter vertical trend anomalies) which we represent in Fig. 4 as a function of the months with contour lines. Isolines of temperature and snow depth (estimated from MeteoSwiss station data) are also shown.

We first note that the anomalies seem to form coherent patterns rather than random variations. We distinguish two main patterns of positive trend anomalies. The first pattern, which is relatively weak in amplitude, occurs in spring to mid summer (April to July) at mid to high altitudes (from $1500 \mathrm{~m}$ asl upward). It appears as a band of positive anomalies closely following the zero-degree isotherm and the snow depth isolines. Another much more pronounced pattern is found in late summer to early winter (August to December) at the lowest altitudes (below $800 \mathrm{~m}$ asl). We interpret other coloured areas as being essentially compensation effects only, since by construction the vertical averages must equal zero.

\section{Effects of atmospheric circulation on Swiss temperatures}

For the period 1959-2008, average temperature trends over Switzerland based on the output of the ENSEMBLES RCMs are in the order of $0.20^{\circ} \mathrm{C} /$ decade, while observation-based northern hemispheric extratropical warming rates, derived from the HadCRUT3v dataset (University of East Anglia and Hadley Centre; Brohan et al., 2006), are of similar magnitude $\left(0.22^{\circ} \mathrm{C} / \mathrm{decade}\right)$. By comparison, Swiss warming rates over the same period have been 1.6 to 1.75 times the above numbers. This raises the question whether these differences may be explained in terms of changes in circulation. Such changes could also be responsible for the observed seasonal variations in trend magnitude, since the effect of changes in circulation may be different from one season to another. Here we use the regression model presented in Section 2.4 to quantify this contribution.

Figure 5 shows the spatially-averaged observed and circulation-derived Swiss temperature series for each of the seasons. The modes of atmospheric variability described by the PC loadings used as explanatory variables are shown in the Appendix (Fig. A1). The calibration period (1959-1983) is represented in lighter colours than the validation period (1984-2008). In general, the circulationderived temperatures reproduce a large part of the observed interannual temperature variations. Compared to the calibration period, the correlation decreases in the validation period, but is still relatively high. The values show a pronounced seasonal cycle, with values being highest in winter and lowest in summer (cf. Table 1).

The observed and circulation-derived trends are summarised in Table 2. The contribution of atmospheric circulation is very variable, but always positive, i.e. changes in circulation have induced an amplification of the warming during the study period. While this contribution is almost negligible in autumn, it is quite substantial in winter, accounting for more than half of the observed trends. On a yearly scale, changes in atmospheric circulation explain more than one third of the trends. The contribution of circulation shows some altitude dependence (dashed lines in Fig. 3), especially in winter and spring, but the structure generally differs from the observations and does not explain the observed altitude dependence of the seasonal trends. After removing the contribution of circulation from the observed trends, the part of the trends not related to circulation (residual trend, see Table 2) varies between 0.15 (autumn) and 0.39 (summer) ${ }^{\circ} \mathrm{C} / \mathrm{decade}$.

\section{RCM-based temperature trends}

The magnitude and altitude dependence of the 1959-2008 trends based on the 21 ENSEMBLES RCMGCM chains shows high seasonal and model-to-model variability (thin grey lines in Fig. 6). Model-tomodel spread is largest in winter and smallest in summer, but the values remain centred around 0.1 to $0.25^{\circ} \mathrm{C} /$ decade (cf. multi-model mean - thick black curve). Except for autumn, the observed trends (thick green line) are at the upper limit of the range of RCM trend values.

There is no clear agreement among models on the vertical structure of the trends. Spring is the only season where most models show similar altitude dependence, with maximum trend values at about 1000 to $1500 \mathrm{~m}$ asl. Such altitude profiles may be related to snow-albedo feedback effects, as discussed earlier in this paper and found by other RCM studies (Im et al., 2010; Giorgi et al., 1997). In the observations, this effect is considerably weaker than in most models, and shifted toward higher altitudes. In summer, a slight tendency toward an increase in trends with altitude is present in many 
RCM-GCM pairs and in the multi-model mean. Here the vertical structure of the multi-model mean looks similar to the observations, except that the stronger trends at low altitudes are not found in the models. In autumn and winter, the differences among models are too large to make any general statements on altitude dependence, although a few models show vertical profiles similar to the observations.

To determine whether the differences between RCM-based and observed trends are linked to changes in circulation, we compare the residual trends (i.e. the part of the observed trend that is independent of atmospheric circulation, cf. Section 2.4.1) with the RCM mean trend (Fig. 6). These circulationcorrected trends (dashed green line) are generally closer to the centre of the distribution of RCM-based trends (solid black line) than the full observed trends (solid green line). This is especially true for winter, where the contribution of circulation seems to explain most of the difference between RCMbased and observed trends. In spring less than half of the difference can be explained, in summer even less, suggesting that most models would underestimate the trends even if changes in atmospheric circulation had not occurred. Finally, in autumn the contribution of circulation is almost negligible in absolute terms and the observations lie within the range of RCM-based trends. Using a slightly different method, van Oldenborgh et al. (2009) also found European winter and spring trends to be considerably influenced by large-scale circulation (their Fig. 6).

\section{Discussion}

\subsection{Modelling of Swiss temperature trends}

We found that a substantial fraction of the interannual variability of Swiss temperatures could be reproduced using synoptic-scale circulation variables only. The contribution of atmospheric circulation to the temperature trends is subject to large seasonal variations, the impact being largest in winter and smallest in autumn (accounting for 53 and 12\% of the observed trends, respectively). The effect of changes in circulation seems to be responsible for most of the difference between observed autumn and winter trends, since the residual trends differ by only $0.04{ }^{\circ} \mathrm{C} / \mathrm{decade}$ (Table 2 ). In their study of North American gridded temperature trends, Abatzoglou and Redmond (2007) explained the differences between autumn and springtime trends in a similar fashion, even though they studied a much larger spatial domain. They showed that changes in atmospheric circulation had a substantial impact on temperature trends, accounting for up to $40 \%$ of observed springtime warming.

Even after removing the contribution of circulation from the observations, the trends are not equally strong in all seasons (cf. Table 2). The residual trends are much stronger in spring and summer than in autumn and winter. In autumn, the estimated residual trend is less than half the value of the spring and summer residual trend. This indicates that atmospheric circulation alone cannot account for all of the observed seasonal differences in trend magnitude. We believe that the differences in the residual trends must be related to physical processes that act on limited temporal and spatial scales. In summer and perhaps to a lesser extent in spring, land-atmosphere interactions have been identified as a possible contribution to higher temperatures (Seneviratne et al., 2006; Fischer et al., 2007) and may be responsible for the stronger residual trends. Also, in spring part of the warming may be explained by snow-albedo feedback effects (see next section), but we expect this effect to be small and limited to mountain regions.

\subsection{Altitude dependence and local effects}

We found the observed trends to be altitude-dependent in spring and in autumn. An important process impacting spring temperatures at mid altitudes is snowmelt. The presence of a snow layer is known to have an influence on air temperatures through the snow-albedo feedback, even though this effect is difficult to quantify (Pepin and Lundquist, 2008). The importance of this effect has been underlined by several model-based studies (Im et al., 2010; Giorgi et al., 1997), but so far little observational evidence based upon surface temperature data has been presented. In a study with observational data, Pepin and Lundquist (2008) found slightly stronger trends close to the zero-degree isotherm and attributed this effect to the snow-albedo feedback, but their analysis was performed on a much larger spatial scale.

The observed positive anomaly in spring at mid altitudes (cf. Fig. 4) indeed seems to be related to snow pack, as the anomaly pattern is situated between the zero and five-degree isotherms and coincides with the timing of snowmelt. Thus, our results indicate the occurrence of slightly stronger warming in spring at altitudes where snow-albedo feedbacks can be expected to be important, i.e. where mean 
temperatures are close to zero or slightly positive. This supports the hypothesis that snow-related processes may have an impact on Swiss Alpine temperature trends. However, it should be noted that the positive anomaly in spring is only a relatively small contribution to the total trends.

The much more pronounced anomaly found in autumn at low altitudes (mainly below $800 \mathrm{~m}$ asl) is not present in the circulation-derived trends (Fig. 3), i.e. it cannot be explained by circulation effects. In Switzerland, a common phenomenon at low altitudes in autumn is the formation of a fog or mist layer below a shallow temperature inversion. Low-visibility events are often associated with wind-calm weather conditions, where cold air pools can form over low-altitude valleys and plains. Because of its special topographical setting between the Alps and the Jura mountains, the Swiss Plateau is subject to frequent cold air pool and low-visibility events in autumn and winter (von Dach, 2006; Troxler and Wanner, 1991; Beniston and Rebetez, 1996).

In recent decades, a clear decline in low-visibility days during autumn-winter has been observed in Europe, and Switzerland was no exception (von Dach, 2006; Vautard et al., 2009). This negative trend is believed to be related to changes in air quality and aerosol concentrations in the first place (Vautard et al., 2009; van Oldenborgh et al., 2010), but land-use changes and urbanisation might also have played a role (Sachweh and Koepke, 1995; van Oldenborgh et al., 2010). Since low-visibility conditions have a net cooling effect at low altitudes by blocking part of the incoming solar radiation, a regional decrease in such phenomena may induce a localised warming in those regions, as shown by Vautard et al. (2009) for European temperatures. Following this reasoning, our hypothesis is that the decline in low-visibility events is also responsible for the observed stronger trends in Swiss lowland regions.

\subsection{Representation of temperature trends in RCMs}

The RCM temperatures are driven by different atmosphere-ocean GCMs, each with its own interannual and decadal climate variability. The fact that the observations are at the upper limit of the range of RCM trends suggests that climate models have generally underestimated the contribution of circulation to the trends. Using another set of climate models, van Oldenborgh et al. (2009) found 1950-2007 climate simulations to underestimate the observed shift towards more westerly circulation in winter (and to a lesser extent in spring).

After subtracting the contribution of changes in circulation from the observations, the trends lie mostly within the range of RCM-based trends (cf. Fig. 6). However, all RCM-GCM pairs but one still predict lower values in summer. This seems to indicate that RCMs would underestimate the trends even if atmospheric circulation had not contributed to stronger warming. A possible cause could be that certain physical processes are not adequately represented in climate models. As shown by van Oldenborgh et al. (2009), part of the discrepancy between models and observations in summer could be explained by a misrepresentation of the effect of soil-atmosphere interactions (see also Schär et al., 2004). Other potential factors are misrepresented declines in aerosols and changes in cloudiness (Wild 2009). Furthermore, the lack of agreement among models on the magnitude and altitude dependence of temperature trends suggests that the representation of local-scale physical processes (and of their effect on temperatures) considerably varies from one model to another. Understanding and quantifying the effect of such processes on temperatures in RCMs would require a much more detailed study that would go beyond the scope of this paper.

\section{Conclusions}

Our trend analysis of 1959-2008 gridded Swiss temperatures showed that the seasonal trends are all positive and highly significant, with an average annual warming rate of $0.35^{\circ} \mathrm{C} / \mathrm{decade}$. Spatial and temporal variability are pronounced on a seasonal scale. The weakest trends (mostly insignificant at the $5 \%$ level) are observed in autumn $\left(0.17^{\circ} \mathrm{C} /\right.$ decade on average), while warming rates peak at $0.46^{\circ} \mathrm{C} /$ decade in summer. In some seasons the patterns of spatial variability are related to elevation. Altitude dependence is strongest in autumn to early winter, with large positive anomalies in lowland regions. Further, anomalously strong trends are also found in spring at mid to high elevations, close to the zero-degree isotherm and to the seasonal altitude limit of snow cover. In other seasons, no clear relationship between trend magnitude and altitude is found.

To better understand the possible effect of changes in atmospheric circulation, we analysed Swiss seasonal temperatures using a multiple regression model with principal components of $500 \mathrm{hPa}$ geopotential height fields as explanatory variables. It was found that a substantial fraction of interannual temperature variability can be predicted using these variables. The contribution of 
atmospheric circulation was positive in all seasons but subject to large seasonal variations, from $0.02^{\circ} \mathrm{C} /$ decade $\left(12 \%\right.$ of the seasonal trend) in autumn to $0.21^{\circ} \mathrm{C} /$ decade $(53 \%)$ in winter. We found this positive contribution to likely explain part of the underestimation of trends in RCMs.

Our results suggest that other physical processes than atmospheric circulation dynamics alone must also contribute to the observed local warming in spring, summer and autumn. The positive trend anomaly at low elevations in autumn could be induced by a decreasing occurrence of low-visibility days in recent decades. In the case of spring, the snow-albedo feedback may be the key process to explain the positive trend anomaly close to the zero-degree isotherm. Other local processes such as soil-atmosphere interactions, aerosol declines and cloudiness decreases may also contribute to the large residual trends in spring and summer, but this hypothesis has not been investigated in detail in this study.

An important implication of this study is that circulation changes and local processes are key parameters in explaining recent western European temperature trends. This suggests that an adequate representation of changes in atmospheric dynamics as well as of other local processes, such as lowvisibility events, snow-albedo feedbacks and soil-atmosphere interactions, may be crucial in obtaining accurate model-based regional warming projections for the next decades.

\section{Acknowledgements}

The authors thank Dr. Christoph Frei for providing the gridded temperature data and for his helpful comments on an earlier version of this paper. Dr. Andreas M. Fischer was supported by the Swiss National Science Foundation through the National Centre for Competence in Research (NCCR) Climate.

\section{References}

Abatzoglou JT, Redmond KT. 2007. Asymmetry between trends in spring and autumn temperature and circulation regimes over western North America. Geophysical Research Letters 34: L18808. DOI: 10.1029/2007GL030891.

Appenzeller C, Begert M, Zenklusen E, Scherrer SC. 2008. Monitoring climate at Jungfraujoch in the high Swiss Alpine region. Science of the Total Environment 391: 262-268. DOI: 10.1016/j.scitotenv.2007.10.005.

Begert M, Schlegel T, Kirchhofer W. 2005. Homogeneous temperature and precipitation series of Switzerland from 1864 to 2000. International Journal of Climatology 25: 65-80. DOI: 10.1002/joc.1118.

Beniston M, Rebetez M. 1996. Regional behavior of minimum temperatures in Switzerland for the period 1979-1993. Theoretical and Applied Climatology 53: 231-243. DOI: 10.1007/BF00871739.

Bradley RS, Keimig FT, Diaz HF. 2004. Projected temperature changes along the American cordillera and the planned GCOS network. Geophysical Research Letters 31: L16210. DOI: 10.1029/2004GL020229.

Brohan P, Kennedy JJ, Harris I, Tett SFB, Jones PD. 2006. Uncertainty estimates in regional and global observed temperature changes: A new data set from 1850. Journal of Geophysical Research 111: D12106. DOI: 10.1029/2005JD006548.

Cleveland WS, Grosse E, Shyu MJ. 1992. Local Regression Models. Chapman and Hall: New York, NY, USA.

Corti S, Molteni F, Palmer TN. 1999. Signature of recent climate change in frequencies of natural atmospheric circulation regimes. Nature 398: 799-802. DOI: 10.1038/19745.

Deng X, Stull R. 2005. A mesoscale analysis method for surface potential temperature in mountainous and coastal terrain. Monthly Weather Review 133: 389-408. DOI: 10.1175/MWR-2859.1.

Fischer EM, Seneviratne SI, Lüthi D, Schär C. 2007. Contribution of land-atmosphere coupling to recent European summer heat waves. Geophysical Research Letters 34: L06707. DOI: 10.1029/2006GL029068.

Giorgi F, Hurrell JW, Marinucci MR, Beniston M. 1997. Elevation dependency of the surface climate change signal: A model study. Journal of Climate 10: 288-296. DOI: 10.1175/15200442(1997)010<0288:EDOTSC>2.0.CO;2. 
Hurrell JW. 1995. Decadal Trends in the North Atlantic Oscillation: Regional Temperatures and Precipitation. Science 269: 676-679. DOI: 10.1126/science.269.5224.676.

Im ES, Coppola E, Giorgi F, Bi X. 2010. Local effects of climate change over the alpine region: A study with a high resolution regional climate model with a surrogate climate change scenario. Geophysical Research Letters 37: L05704. DOI: 10.1029/2009GL041801.

IPCC. 2007a. Climate Change 2007: Impacts, Adaptation and Vulnerability. Contribution of Working Group II to the Fourth Assessment Report of the Intergovernmental Panel on Climate Change [Parry ML, Canziani OF, Palutikof JP, van der Linden PF and Hanson CE (eds.)]. Cambridge University Press: Cambridge, UK.

IPCC. 2007b. Climate Change 2007: The Physical Science Basis. Contribution of Working Group I to the Fourth Assessment Report of the Intergovernmental Panel on Climate Change [Solomon S, Qin D, Manning M, Chen Z, Marquis M, Averyt KB, Tignor M and Miller HL (eds.)]. Cambridge University Press: Cambridge, UK.

Kalnay E, et al. 1996. The NCEP/NCAR 40-Year Reanalysis Project. Bulletin of the American Meteorological Society 77: 437-472. DOI: 10.1175/1520-0477(1996)077<0437:TNYRP >2.0.CO;2.

Kendall MG. 1975. Rank Correlation Methods. Charles Griffin: London, UK.

Mann HB. 1945. Nonparametric tests against trend. Econometrica 13: 245-259. DOI: $10.2307 / 1907187$.

OcCC. 2007. Climate Change and Switzerland 2050. Expected Impacts on Environment, Society and Economy. OcCC/ProClim-: Berne, Switzerland.

Pepin NC, Lundquist JD. 2008. Temperature trends at high elevations: Patterns across the globe. Geophysical Research Letters 35: L14701. DOI: 10.1029/2008GL034026.

Pepin NC, Seidel DJ. 2005. A global comparison of surface and free-air temperatures at high elevations. Journal of Geophysical Research 110: D03104. DOI: 10.1029/2004JD005047.

Philipona R, Behrens K, Ruckstuhl C. 2009. How declining aerosols and rising greenhouse gases forced rapid warming in Europe since the 1980s. Geophysical Research Letters 36: L02806. DOI: 10.1029/2008GL036350.

Rebetez M, Reinhard M. 2007. Monthly air temperature trends in Switzerland 1901-2000 and 19752004. Theoretical and Applied Climatology 91: 27-34. DOI: 10.1007/s00704-007-0296-2.

Sachweh M, Koepke P. 1995. Radiation fog and urban climate. Geophysical Research Letters 22: 1073-1076. DOI: 10.1029/95GL00907.

Sakamoto Y, Ishiguro M, Kitagawa G. 1986. Akaike Information Criterion Statistics. D. Reidel: Dordrecht/Tokyo.

Schär C., Vidale PL, Lüthi D, Frei C, Häberli C, Liniger MA, Appenzeller C. 2004. The role of increasing temperature variability in European summer heatwaves. Nature 427: 332- 336.

Seneviratne SI, Lüthi D, Litschi M, Schär C. 2006. Land-atmosphere coupling and climate change in Europe. Nature 443: 205-209. DOI: 10.1038/nature05095.

Troxler FX, Wanner H. 1991. Nebelkarten der Schweiz. Geographica Helvetica 46: 21-31.

van der Linden P, Mitchell JFB (eds.). 2009. Climate change and its impacts: summary of research and results from the ENSEMBLES project. Met Office Hadley Centre: Exeter, UK.

van Oldenborgh GJ, Drijfthout S, van Ulden A, Haarsma R, Sterl A, Severijns C, Hazeleger W, Dijkstra H. 2009. Western Europe is warming much faster than expected. Climate of the Past 5: 1-12. DOI: $10.5194 / \mathrm{cp}-5-1-2009$.

van Oldenborgh GJ, Yiou P, Vautard R. 2010. On the roles of circulation and aerosols in the decline of mist and dense fog in Europe over the last 30 years. Atmospheric Chemistry and Physics 10: $4597-$ 4609. DOI: 10.5194/acp-10-4597-2010.

Vautard R, Yiou P. 2009. Control of recent European surface climate change by atmospheric flow. Geophysical Research Letters 36: L22702. DOI: 10.1029/2009GL040480.

Vautard R, Yiou P, van Oldenborgh GJ. 2009. Decline of fog, mist and haze in Europe over the past 30 years. Nature Geoscience 2: 115-119. DOI: 10.1038/ngeo414.

von Dach L. 2006. Nebelhäufigkeit in der Schweiz: Entwicklung und Trends im Winterhalbjahr von 1864 bis 2006. Master's thesis, Geografisches Institut der Universität Bern: Berne, Switzerland.

Wild M. 2009. Global dimming and brightening: A review. Journal of Geophysical Research 114: D00D16. DOI:10.1029/2008JD011470. 
Wild M, et al. 2005. From dimming to brightening: Decadal changes in solar radiation at Earth's surface. Science 308: 847-850. DOI: 10.1126/science.1103215.

Wilks DS. 2005. Statistical Methods in the Atmospheric Sciences. Academic Press: New York, NY, USA.

\section{Appendix}

\section{A1. Atmospheric circulation patterns and corresponding temperature anomalies}

Considering the circulation patterns described by the PCs of $500 \mathrm{hPa}$ geopotential height fields, the corresponding estimated temperature anomalies make sense from a physical perspective in all cases. For instance, the first PC, which describes a mild southwesterly flow over Central Europe (NAO-like pattern), is associated with strong positive temperature anomalies, in line with expectations (Hurrell, 1995).

A careful examination of the spatial distribution of the temperature anomalies reveals that some circulation patterns induce altitude-dependent effects (see e.g. PC3 in Fig. A1 a). This implies that trends in the frequency of occurrence of particular weather patterns could lead to altitudinal differences in temperature trends.

To assess the importance of trends in circulation patterns, we analysed the time series of the 10 first geopotential height PC scores for each season (not shown). We found that in some seasons a few PC scores had statistically significant trends. In particular, the first PC featured a significant trend in winter toward a stronger southwesterly circulation over Europe. This is consistent with results from previous studies showing a tendency toward higher NAO index values over recent decades (van Oldenborgh et $a l ., 2009$ ), and may explain part of the positive contribution of atmospheric circulation to the observed winter trends. In general, however, the net effect of circulation on temperatures was difficult to estimate due to the complexity of the temperature anomaly patterns and to the relatively large number of PCs.

\section{Tables and Figures}

Table 1: Correlation between observed and circulation-derived temperatures in the calibration (1959$1983)$ and validation (1984-2008) periods.

\begin{tabular}{|c|c|c|c|c|c|}
\hline & DJF & MAM & JJA & SON & Year \\
\hline calibration & 0.97 & 0.91 & 0.90 & 0.93 & 0.93 \\
\hline validation & 0.83 & 0.55 & 0.45 & 0.80 & 0.67 \\
\hline
\end{tabular}

Table 2: Magnitude of observed, circulation-derived, residual and RCM-based temperature trends $\left({ }^{\circ} \mathrm{C} /\right.$ decade) in the 1959-2008 period. The contribution of atmospheric circulation is also expressed relative to the observed trends (in percent). Due to rounding errors, the annual trends may slightly differ from the average of the seasonal values.

\begin{tabular}{|c|c|c|c|c|c|}
\hline & DJF & MAM & JJA & SON & Year \\
\hline observed & 0.40 & 0.39 & 0.46 & 0.17 & 0.35 \\
\hline circulation & $0.21(53 \%)$ & $0.08(21 \%)$ & $0.07(15 \%)$ & $0.02(12 \%)$ & $0.13(37 \%)$ \\
\hline residual & 0.19 & 0.31 & 0.39 & 0.15 & 0.22 \\
\hline RCMs & 0.16 & 0.18 & 0.16 & 0.24 & 0.18 \\
\hline
\end{tabular}



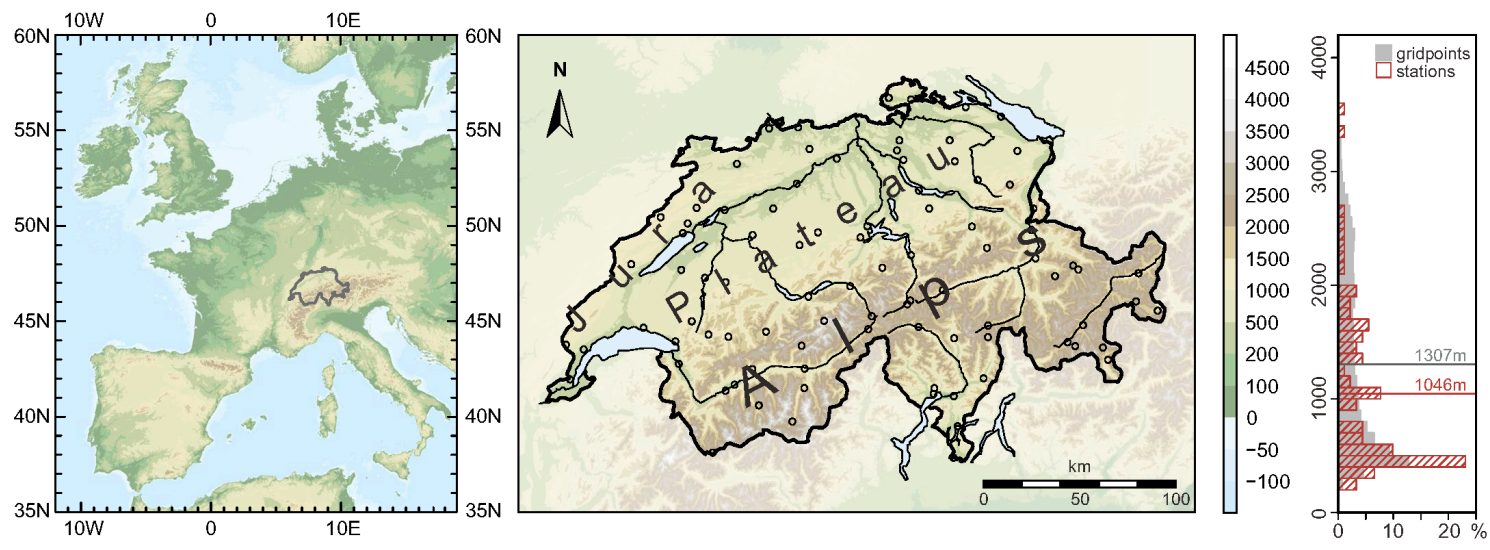

Fig. 1: Swiss topography (middle) and setting within Western Europe (left). Main Swiss geographical areas are indicated. Open black circles denote temperature measurement stations which were used for gridding. The height distribution of the gridpoint topography and of the measurement stations is also shown (right).
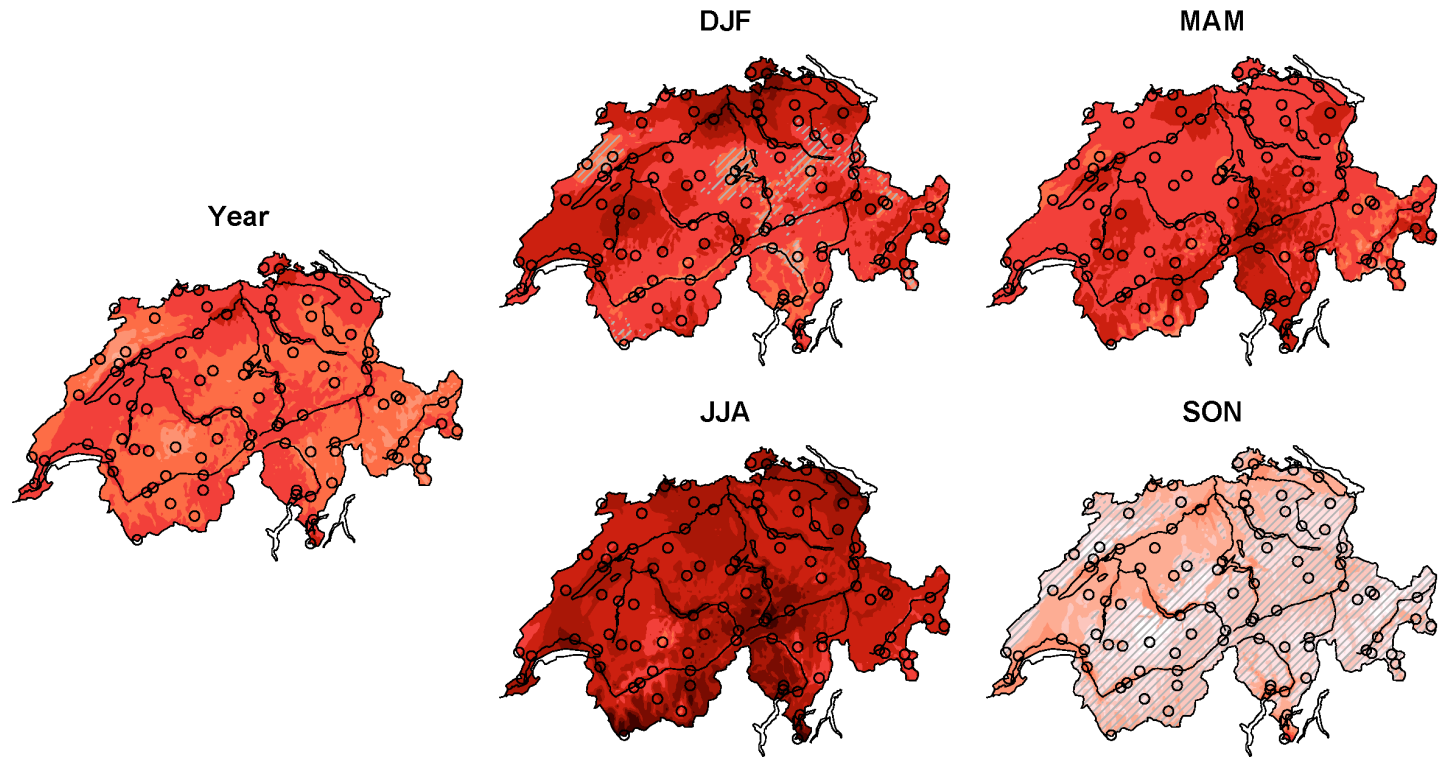

$\begin{array}{llllllllllll}0 & 0.05 & 0.1 & 0.15 & 0.2 & 0.25 & 0.3 & 0.35 & 0.4 & 0.45 & 0.5 & 0.55\end{array}$

Fig. 2: Swiss seasonal and annual temperature trends 1959-2008 $\left({ }^{\circ} \mathrm{C} /\right.$ decade). Hatched areas represent non-significant trends at the 5\% level. Open black circles denote temperature measurement stations which were used for gridding. 

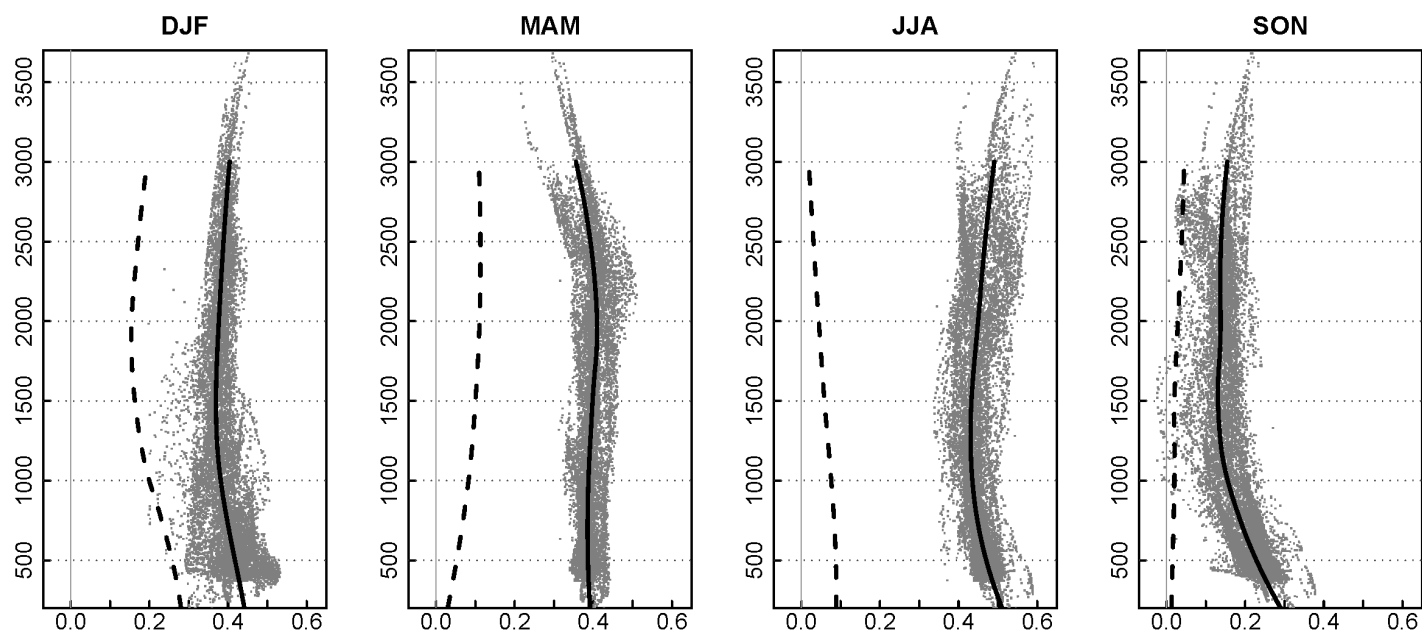

Fig. 3: Vertical profiles of seasonal temperature trends. The grey dots denote the magnitude of observed temperature trends at individual gridpoints, while the vertical black curves represent LOESS fits of the observed (solid) and circulation-derived (dashed) trends (see Section 4 for details on the statistically modelled temperatures). The zero-trend line is represented by a thin vertical grey line.

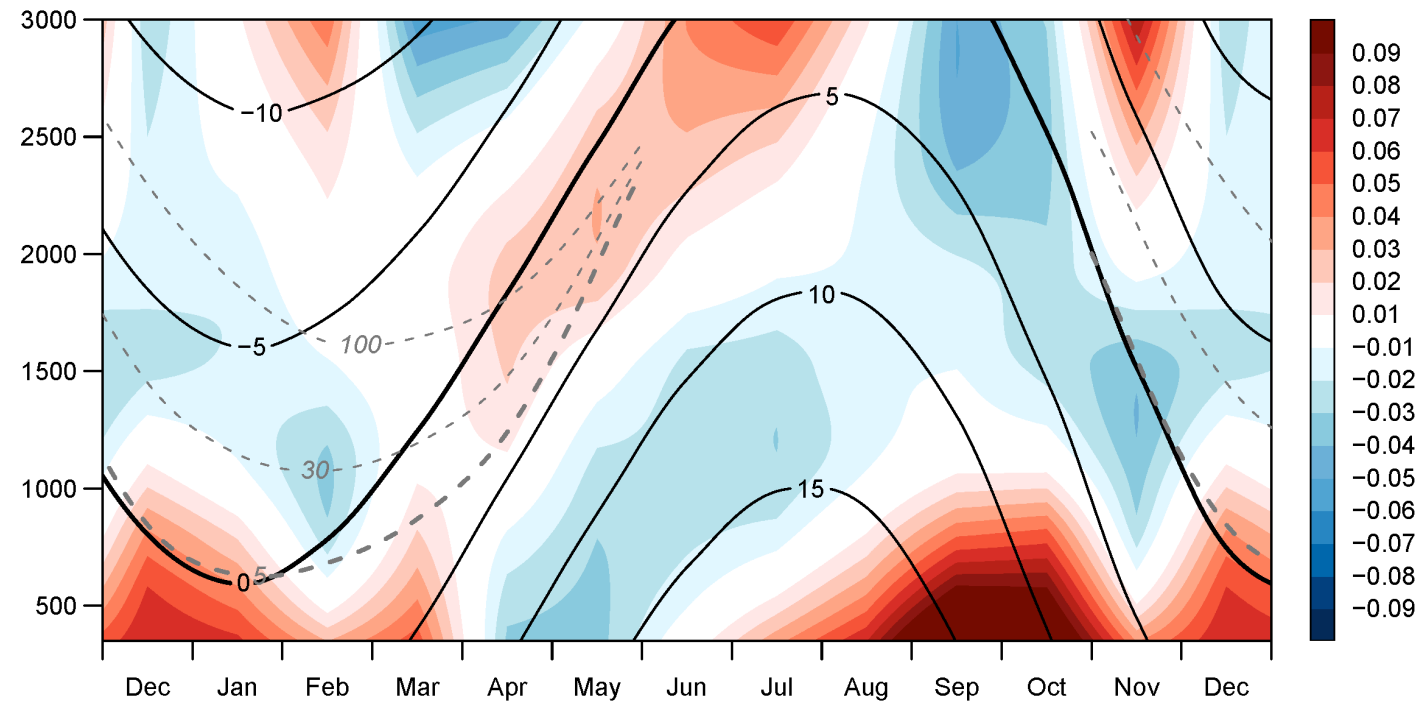

Fig. 4: Vertical anomalies of observed temperature trends in ${ }^{\circ} \mathrm{C} / \mathrm{decade}$ (see text for details on the construction of trend anomalies). The solid black lines denote estimated temperature isotherms $\left({ }^{\circ} \mathrm{C}\right)$, while the dashed grey lines represent isolines of 5, 30 and $100 \mathrm{~cm}$ snow depth. 

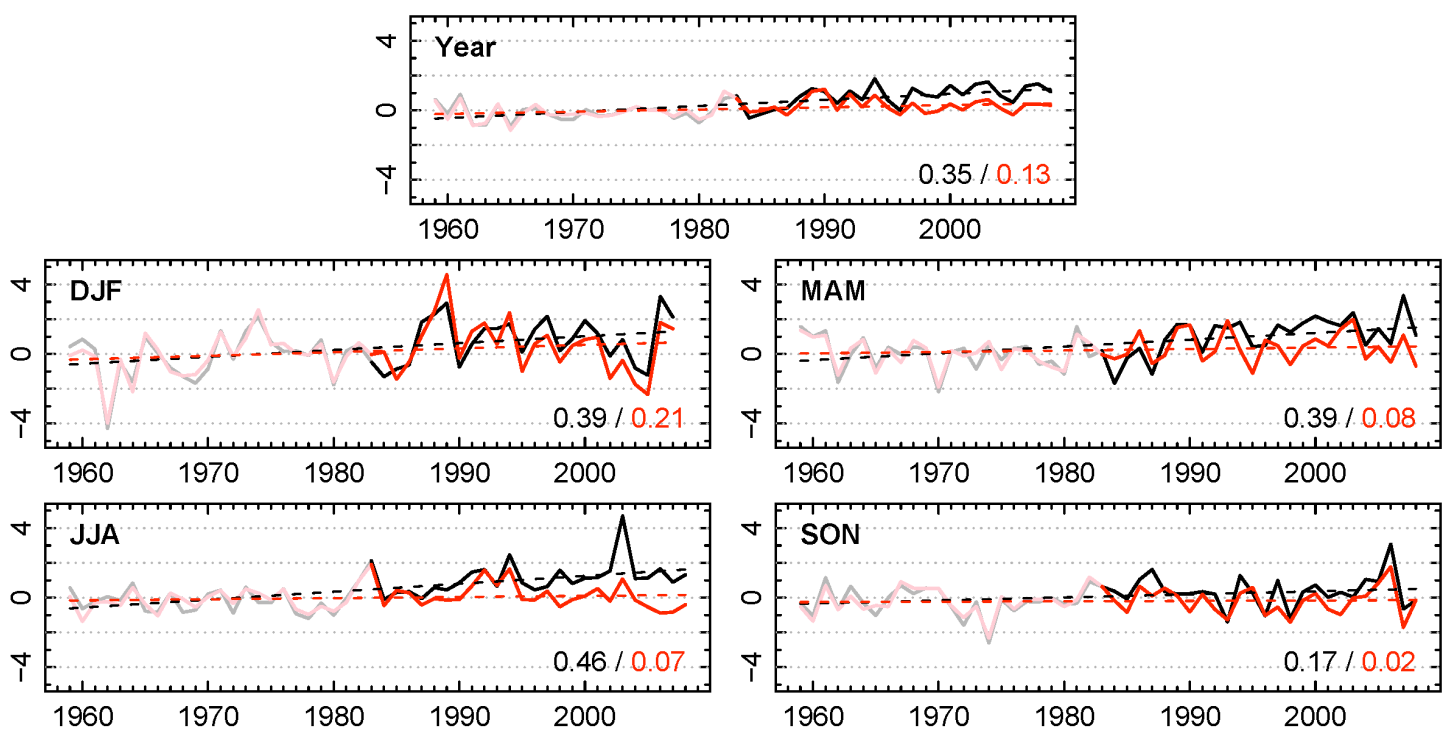

Fig. 5: Spatially-averaged temperature anomalies for Switzerland $\left({ }^{\circ} \mathrm{C}\right)$ and estimated linear trends 1959-2008 (bottom right corner). Black and red colours denote the observed and circulation-derived series, respectively. The calibration period 1959-1983 (first half of the time series) is shown in lighter colours. The dashed lines represent the linear trend lines for 1959-2008.
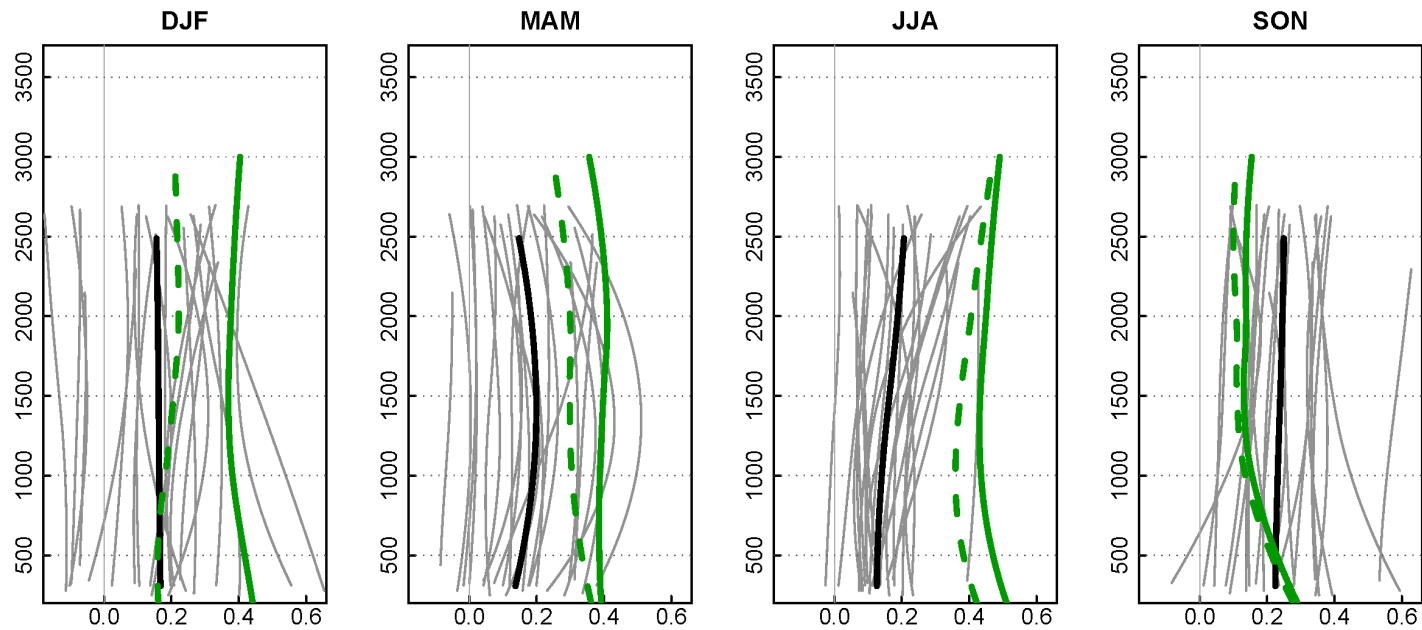

Fig. 6: Vertical profiles of RCM-based and observed temperature trends. The grey curves are LOESSsmoothed trend values for each of the 21 RCM-GCM chains, while the black curve represents the multi-model mean. The green curves denote observed (solid) and residual trends (dashed). The height ranges of the RCMs vary because of the different representations of topography. 
a

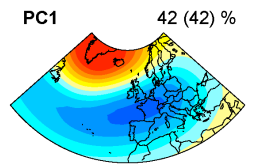

PC6

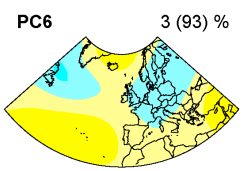

PC1

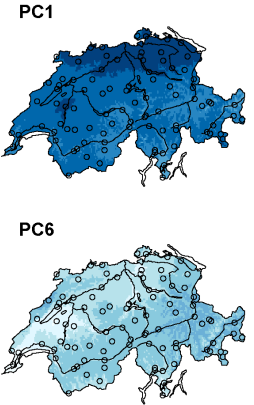

b $\quad \mathrm{PC} 1$
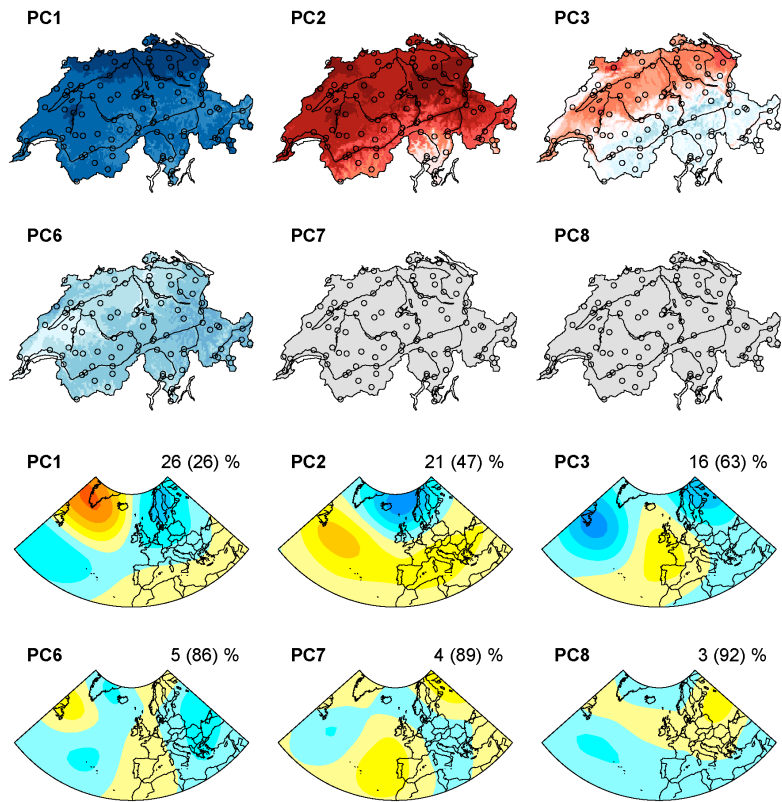

PC8
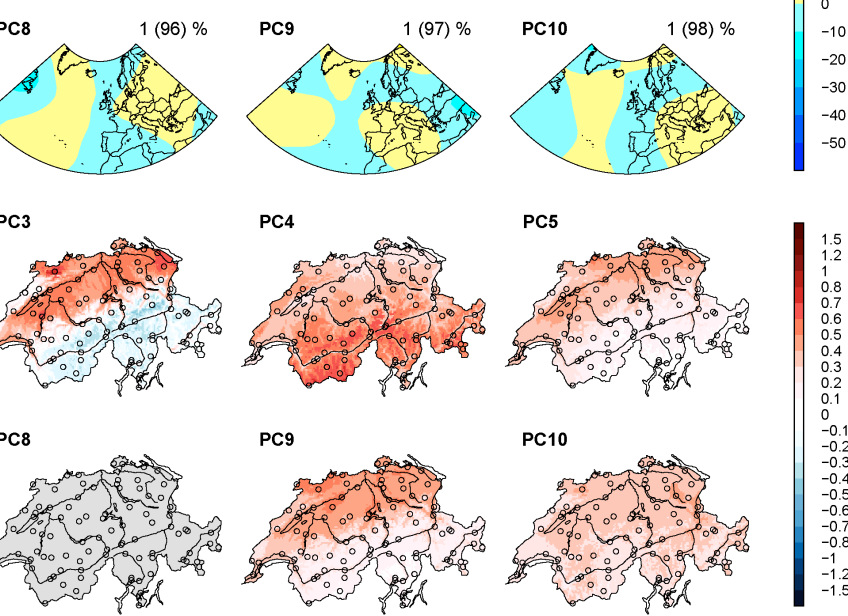

PC5

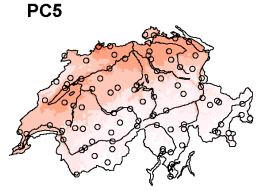

PC10

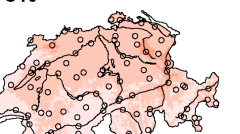

हlo:
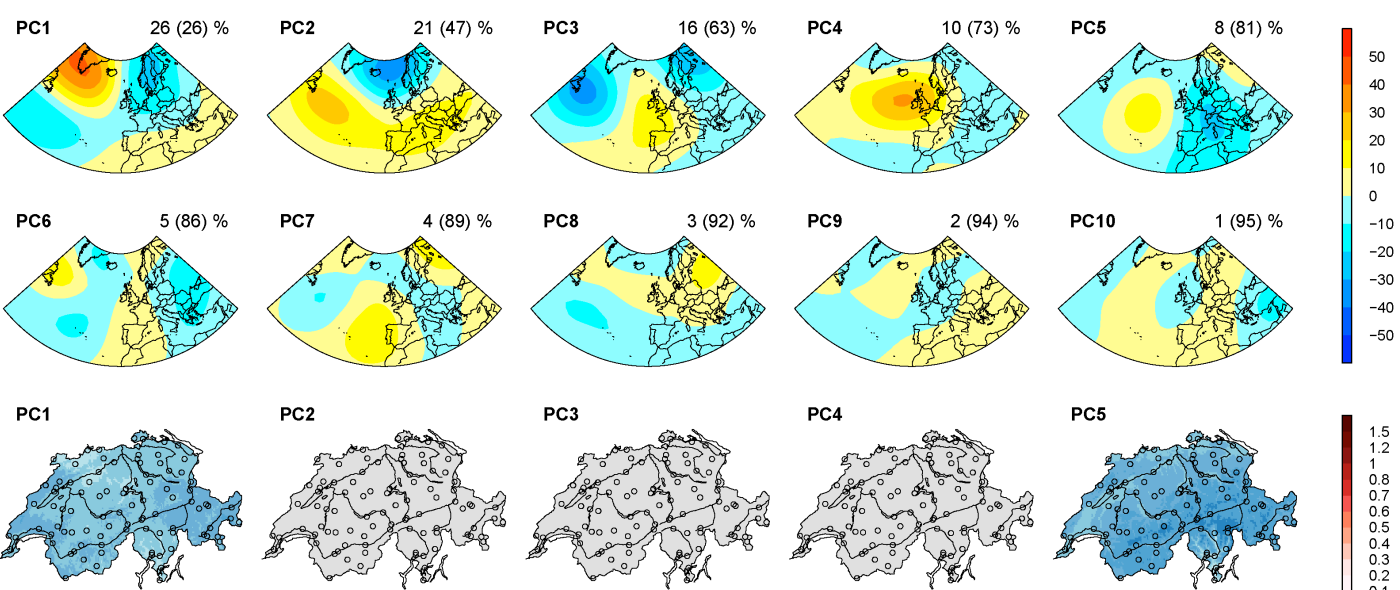

PC2
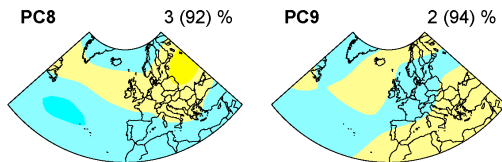

PC3

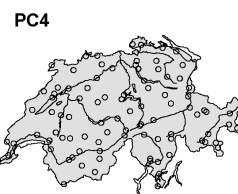

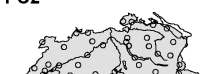

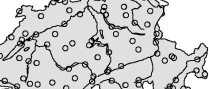

bin
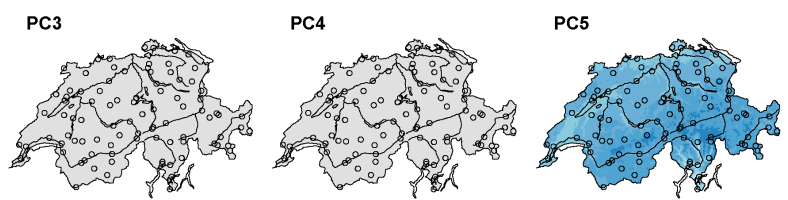

PC9

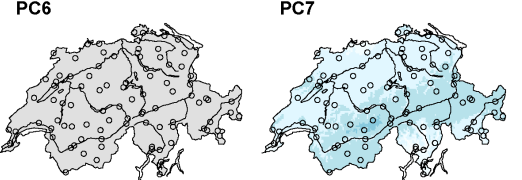

PC8

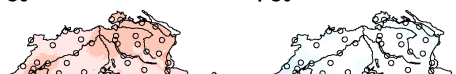

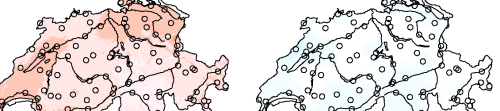

PC10

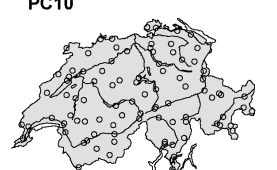

1.5
1.2
0.8
0.7
0.7
0.5
0.5
0.3
0.3
0.2
0.1
0.1
0.1
-0.2
-0.3
-0.4
-0.5
-0.6
-0.7
-0.8
-1.2
-1.5
-1.5 
C
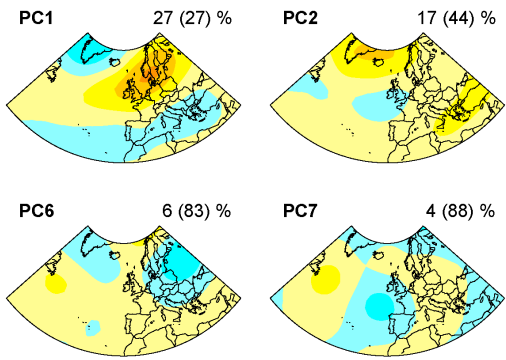

PC1

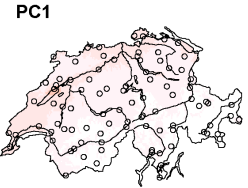

PC2

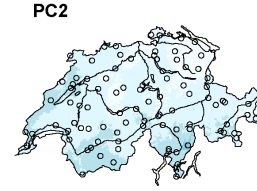

PC6

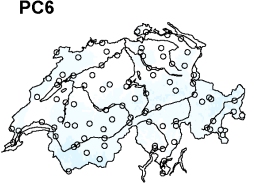

PC7
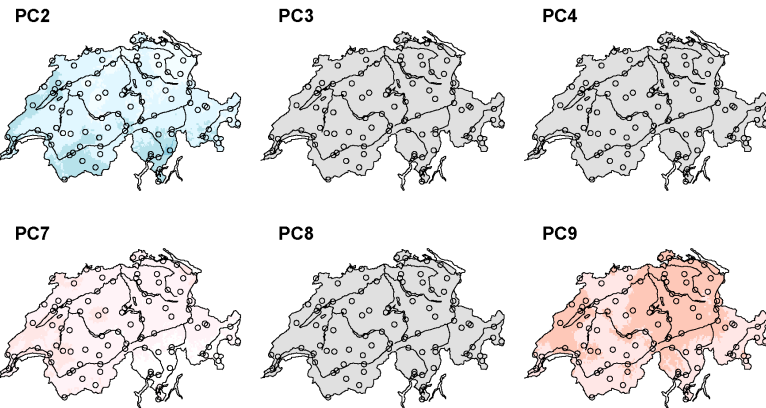

PC9
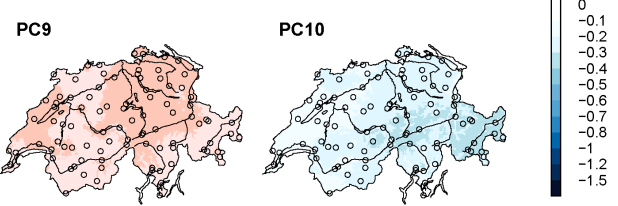

d
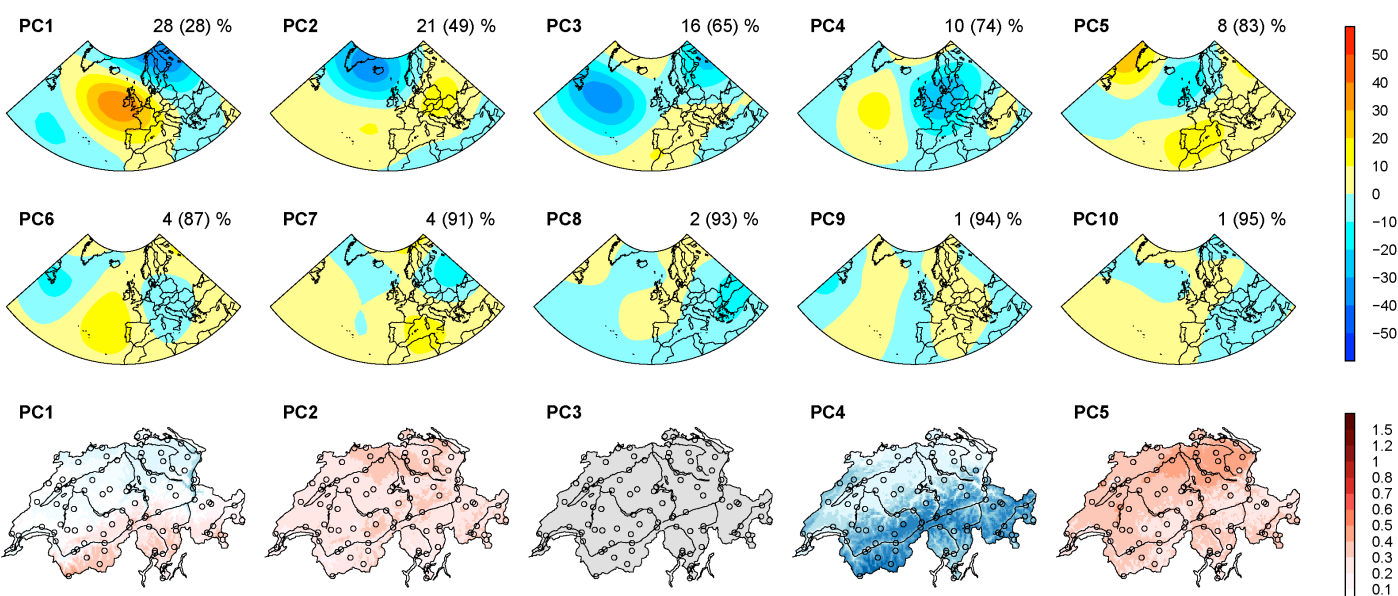

PC8
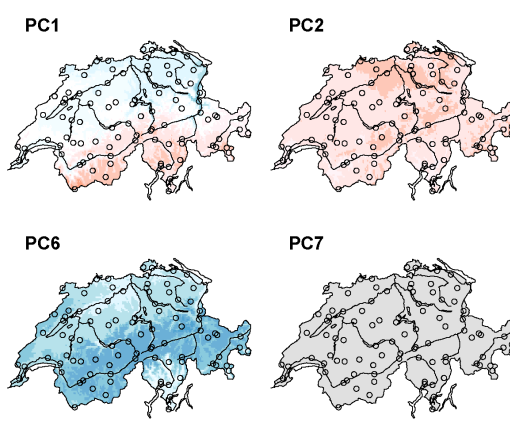

PC7
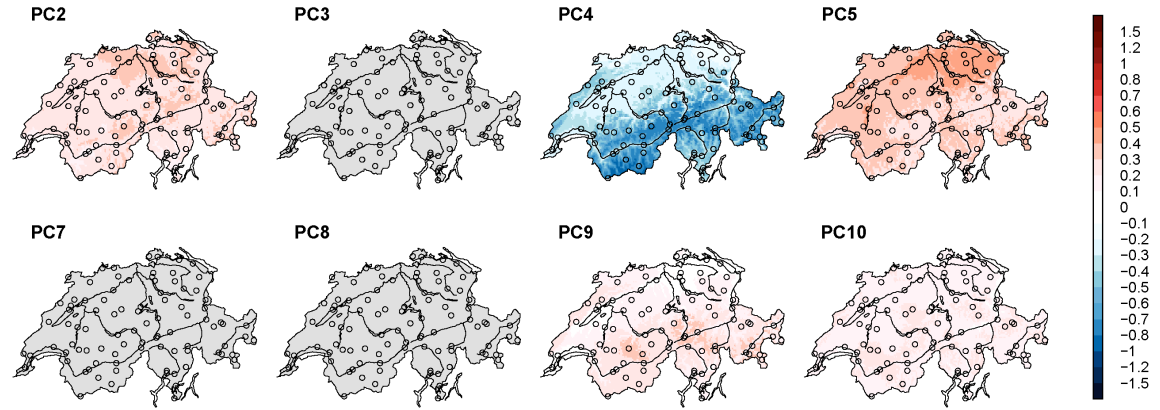

Fig. A1: Top: First 10 PC loadings of $500 \mathrm{hPa}$ seasonally-averaged DJF geopotential height fields, multiplied by one standard deviation $(\mathrm{m})$. The cumulative explained variance fraction is given in the top right corner of each figure. Bottom: Temperature anomalies induced by an anomaly of the corresponding PC of one standard deviation $\left({ }^{\circ} \mathrm{C}\right.$ ). (a) DJF, (b) MAM, (c) JJA, (d) SON. Grey colouring denotes PCs that were not selected by the stepwise regression model. 